\title{
PEMANFAATAN TENAGA MATAHARI SEBAGAI PENGGERAK TURBIN AIR MENGHASILKAN PEMBANGKIT LISTRIK HIDRO BUATAN DI DESA CIMARAGAS KECAMATAN CIMARAGAS KABUPATEN CIAMIS
}

\section{UTILIZATION OF SOLAR POWER AS A WATER TURBINE PRODUCING AN ARTIFICIAL HYDRO POWER PLANT IN CIMARAGAS VILLAGE, CIMARAGAS DISTRICT, CIAMIS REGENCY}

\author{
Ida Farida ${ }^{1 *}$, Yat Rospia Brata ${ }^{2}$, Zenal Abidin $^{3}$ \\ ${ }^{1}$ Fakultas Hukum Universitas Galuh \\ ${ }^{2}$ FKIP Universitas Galuh \\ ${ }^{3}$ Fakultas Teknik Universitas Galuh \\ *Email: idafarida.galuh@gmail.com \\ (Diterima 28-08-2021; Disetujui 15-09-2021)
}

\begin{abstract}
ABSTRAK
Mitra kegiatan pengabdian kepada masyarakat yang dikemas dalam penerapan Program Teknologi yang Didiseminasikan kepada masyarakat (PTDM) ini, adalah kelompok Pelayanan Teknologi Tepat Guna (Posyantek) Gasma yang berada di Desa Cimaragas Kecamatan Cimaragas Kabupaten Ciamis. Adapun permasalahan yang dihadapi oleh mitra yaitu meningkatnya beban dan pembayaran listrik di masyarakat sehingga banyak diantarnya warga yang mengalami pemutusan listrik dari pihak Perusahan Listrik Negara (PLN). Selain itu, adanya pendirian industri besar yang senantiasa banyak menimbulkan pencemaran berupa polusi di masyarakat. Berdasarkan atas analisa situasi tersebut, selanjutnya solusi yang ditawarkan untuk mengatasi permasalahan tersebut, yaitu dengan memberikan penguatan terhadap kelompok pencinta lingkungan dan pemanfaatan sinar matahari untuk energi listrik di lingkungan masyarakat. Tahapan-tahapan dalam pelaksanaan kegiatan penerapan Program Teknologi yang Didiseminasikan kepada masyarakat (PTDM) meliputi: 1) Tahap Survey Kegiatan; 2) Tahap Pendampingan 3) Tahap Diseminasi Teknologi berupa praktek penerapan IPTEK 4) Tahap Evaluasi dan tindaklanjut. Hasil pelaksanaan kegiatan adalah mitra telah mengalami perubahan berupa peningkatkan kapasitas dan kemampuan diri atau live skill khususunya dalam perakitan dan pembuatan teknologi Listrik Hidro Buatan dengan memanfaatkan energi matahari, sekaligus sebagai kesempatan dan peluang untuk mitra dalam mengembangkan hasil teknologi yang lebih memberikan dampak bagi peningkatan kesejahteraan masyarakat dan peningkatan tarap sosial masyarakat.
\end{abstract}

Kata Kunci : Listrik Hidro, Energi Sinar Matahari

\begin{abstract}
Partners of community service activities that are packaged in the implementation of the Technology Disseminated Program (PTDM), are the Gasma Appropriate Technology Service (Posyantek) group located in Cimaragas Village, Cimaragas District, Ciamis Regency. The problems faced by partners are the increasing burden and payment of electricity in the community so that many residents experience power cuts from the State Electricity Company (PLN). In addition, the establishment of large industries that always cause a lot of pollution in the form of pollution in the community. Based on the analysis of the situation, further solutions are offered to overcome these problems, namely by providing reinforcement to environmental groups and the use of sunlight for electrical energy in the community. The stages in the implementation of the implementation of the Technology Program Disseminated to the public (PTDM) include: 1) Activity Survey Stage; 2) Assistance Phase 3) Technology Dissemination Phase in the form of the practice of applying science and technology 4) Evaluation and follow-up phase. The result of the implementation of the activity is that partners have experienced changes in the form of increasing their capacity and abilities or live skills, especially in assembling and manufacturing Artificial Hydro Electricity technology by utilizing solar energy, as well as opportunities and opportunities for partners in developing technological results that have a greater impact on improving people's welfare. and increasing social standards of society.
\end{abstract}

Keywords: Hydro Electricity, Solar Energy 
Pemanfaatan Tenaga Matahari Sebagai Penggerak Turbin Air Menghasilkan Pembangkit Listrik Hidro Buatan di Desa Cimaragas Kecamatan Cimaragas Kabupaten Ciamis

Ida Farida, Yat Rospia Brata, Zenal Abidin

\section{PENDAHULUAN}

Desa Cimaragas Kecamatan Cimaragas Kabupaten Ciamis meupakan kecamatan yang diapit oleh dua kecamatan/kota, yaitu Desa Cineam Kabupaten Tasikmalaya serta Kota Banjar. Sebagian besar wilayah Desa Cimaragas adalah lahan pertanian dan perumahan. Desa Cimaragas juga merupakan desa yang memiliki banyak potensi yang patut dikembangkan diantaranya menyeruak ke permukaan mengenai masalah pemanfaatan energi matahari untuk menggerakkan turbin air sebagai pembangkit listrik. Hal ini dikarenakan permasalahan pemanfaatan energi matahari relatif tanpa biaya serta cocok dikembangkan di daerah tropis meskipun biaya awal relatif mahal. Menurut Jatmiko dkk (2012), turbin air berperan untuk mengubah energi air (energi potensial, tekanan dan energi kinetik) menjadi energi mekanik dalam bentuk putaran poros. Putaran poros turbin ini akan diubah oleh generator menjadi tenaga listrik.

Dalam kegiatan aktifitas sehari-hari, masyarakat membutuhkan energi alternatif untuk memecahkan masalah biaya listrik yang mahal karena pembebanan litrik untuk penerangan jalan dibebankan kepada masyarakat. Desa Cimaragas yang jaraknya tidak lebih dari $20 \mathrm{KM}$ dari pusat kota Ciamis, alat penerangan listrik tidak menjadi permasalahan, tetapi karena jarak dari pusat kota yang tidak begitu jauh masyarakat banyak yang menginginkan sepanjang jalan menuju desa dapat diterangi listrik dan pemerintah merespon kebutuhan tersebut dengan membangun tiang-tiang listrik sepanjang jalan di wilayah tersebut, tetapai ternyata setelah diketahui oleh masyarakat bahwa penerangan listrik yang dipasang di jalan-jalan menuju pelosok di desa Cimaragas biayanya dibebankan kepada masyarakat. Sehingga dengan penemuan pembangkit listrik tenaga matahari ini merupakan solusi dalam memecahkan masalah kebutuhan akan listrik dengan biaya relatif murah.

Tim LPPM Universitas Galuh berusaha untuk memberikan sosialisasi tentang cara pemanfaatan energi matahari yang akan dimanfaatkan untuk menggerakkan turbin air kemudian diolah menjadi energi listrik yang merupakan energi terbarukan dan sinar matahari di daerah tropis ini ada sepanjang tahun. Cara kerja Alat Pembangkit Listrik Tenaga Surya yang menggerakan turbin air menghasilkan energi listri hidro buatan ini merupakan teknologi sederhana yang diambil dengan prinsip memanfaatakan energi matahari yang dimasukan ke dalam solar sistem dari tenaga solar sistem ini, kemudian menggarakan turbin air dimana jatuhnya air dari tempat yang lebih tinggi ke tempat yang lebih rendah. Dibutuhkan sebuah wadah penampung air yang diletakkan di ketinggian 8 meter. Melalui pipa, air dalam penampungan tersebut kemudian dialirkan untuk 
menggerakkan turbin mini, berupa dinamo yang nantinya akan mampu menghasilkan listrik dengan daya 440-900 watt. Ada dua dinamo dimana satu dinamo mempunyai tugas untuk membangkitkan listrik, sementara dinamo yang lain bertugas mengatur aliran air ke atas penampungan yang berjalan seimbang dan berkelanjutan.

Listrik untuk penerangan jalan di desa sementara masih menggunakan listrik PLN yang biayanya dibebankan kepada masyarakat. Padahal dengan berlimpahnya energi matahari yang tanpa biaya, praktis dan hemat, energi yang tidak pernah habis, terbarukan, bersih dan ramah lingkungan dan praktis dengan kemandirian energi warga Desa Cimaragas bisa dirintis. Selain itu, juga masalah beban masyarakat untuk membayar biaya penerangan jalan di desa menjadi hilang sama sekali.

Selanjutnya, dengan melihat pada hasil analisa situasi yang dihubungkan dengan pendekatan SWOT dan berasarkan dari hasil Focus Group Discusion (FGD) diperoleh beberapa permasalahan yang dihadapi mitra saat ini sebagai prioritas untuk segera dipecahkan. Untuk lebih jelasnya mengenai gambaran analisa permasalahan diuraikan dalam matrik sebagaimana terlihat pada Tabel 1.

Tahel 1. Matrik Analisis SWOT Keadaan Permasalahan Mitra

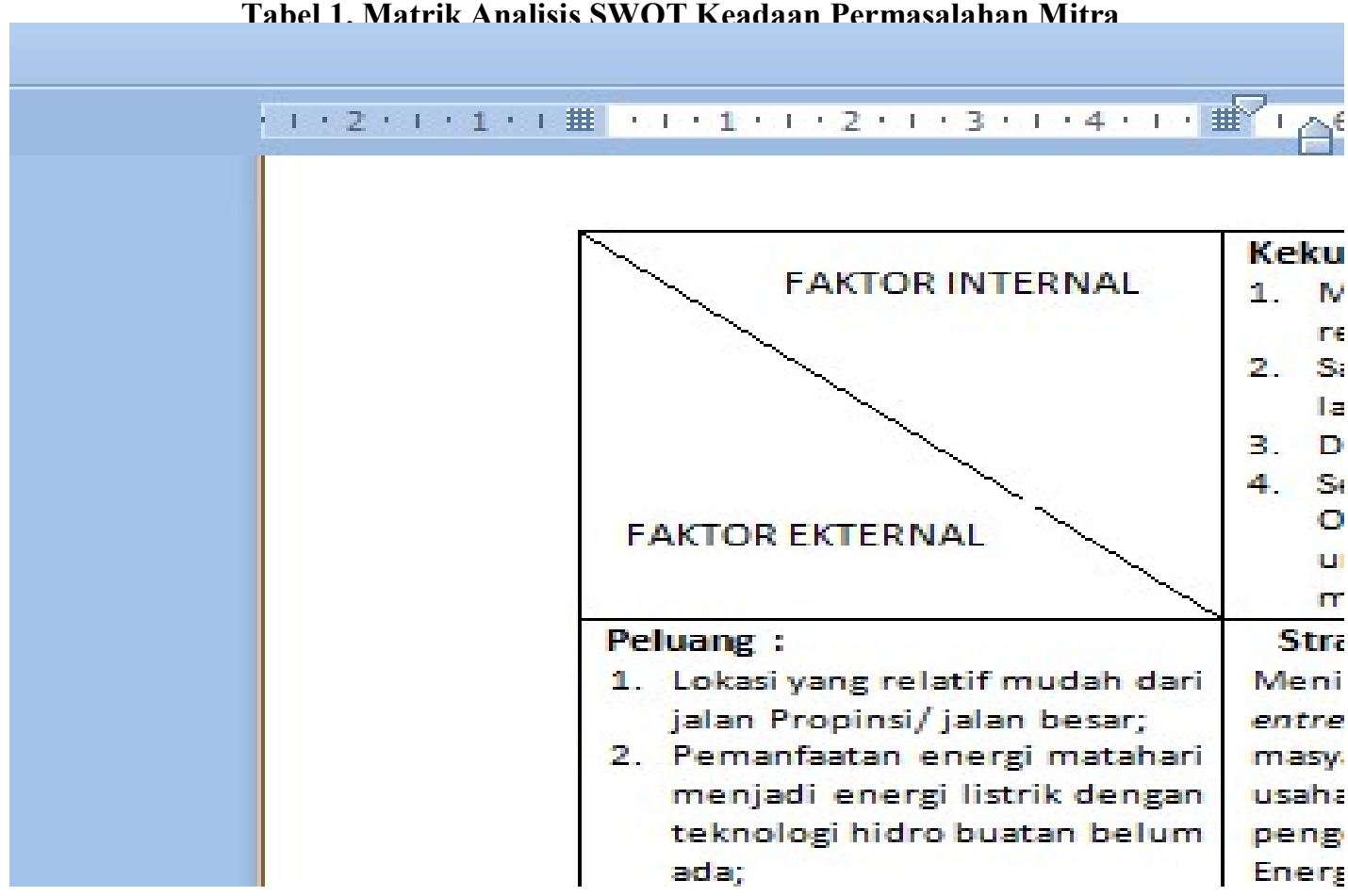

Hasil pemetaan lingkungan menunjukan bahwa kebutuhan listrik murah untuk penerangan jalan merupakan permasalahan utama. Energi matahari sangat besar dan belum dimanfaatkan secara maksimal. Melihat potensi tersebut maka kegiatan ini akan diproyeksikan pada pemanfaatan energi matahari sebagai penggerak turbin air untuk menghasilkan listrik hidro dan turunannya seperti sosialiasasi dan pelatihan mengenai teknik pemanfaatan sinar matahari 
Pemanfaatan Tenaga Matahari Sebagai Penggerak Turbin Air Menghasilkan Pembangkit Listrik Hidro Buatan di Desa Cimaragas Kecamatan Cimaragas Kabupaten Ciamis

Ida Farida, Yat Rospia Brata, Zenal Abidin

yang ditangkap oleh solar sel yang menghasilkan arus listrik elektonik DC masuk ke dalam Accu dan dirubah dari DC ke AC yang dipergunakan untuk menggerak air dari lembah ke ketinggian dengan menggunakan mesin air dengan menggunakan pipa mengalirkan air dengan tekanan yang akan menggerakkan turbin dari perputaran turbin akan masuk ke dinamo dan menghasilkan aliran listrik AC.

Menurut Syarif dkk (2019), salah satu energi alternatif yang berpotensi dimanfaatkan di Indonesia adalah energi air. Indonesia memiliki iklim tropis serta curah hujan tinggi sehingga melalui pemanfaatan secara luas maka kebutuhan energi listrik dapat terpenuhi bahkan di daerah pedesaan. Menurut Sunardi (2019), pembangkit listrik mikro hidro pada prinsipnya memanfaatkan beda ketinggian dan jumlah debit air per detik yang ada pada aliran air. Menurut Aziz dan Fitri (2020), semakin besar kapasitas aliran maupun ketinggiannya dari instalasi maka semakin besar energi yang bisa dimanfaatkan untuk menghasilkan energi listrik. Menurut Misbachudin (2016), tinggi jatuh tergantung kepada geografi lokasi. Pada dasarnya pembangkit mikro hidro digolongkan dalam dua kategori yang menentukan jenis turbin yang akan dipakai yaitu tinggi jatuh rendah yang dihitung dari titik 0 (nol) sampai 20 meter dan tinggi jatuh yang lebih dari 20 meter

\section{BAHAN DAN METODE}

Pelaksanaan kegiatan pengabdian kepada masyarakat yang dikemas dalam bentuk Program Teknologi yang Didiseminasikan kepada masyarakat (PTDM) menggunakan metode pendampingan dalam meningkatkan pengetahuan dan pengembangan pola pikir mitra sehingga dapat meningkatkan kapasitas dan kemampuan diri atau live skill. Adapun tahapan dari pelaksanaan kegiatan tersebut meliputi: 1) Tahap Survey Kegiatan; 2) Tahap Pendampingan, 3) Tahap Diseminasi Teknologi berupa praktek penerapan IPTEK, dan 4) Tahap Evaluasi dan tindaklanjut.

\section{HASIL DAN PEMBAHASAN}

Pelaksanaan kegiatan PTDM diawali dari persiapan awal yang tujuannya untuk melihat dan menilai sejauhmana keinginan dan partisipasi mitra dalam pelaksanaan program serta dukungan dari pemerintah desa setempat. Disamping itu, pada kegiatan tahap 1 ini dilakukan pula pendataan oleh pemerintah desa terakit dengan peserta dari masyarakat yang bersedia mengikuti pelatihan. Berdasarkan dari data yang melakukan registrasi dan mengisi form kesediaan diperoleh sebanyak 20 orang masyarakat yang bersedia mengikuti pelatihan penerapan teknologi Listrik Hidro Buatan dengan memanfaatkan energi matahari. 
Setelah pelaksanaan kegiatan tersebut, dilaksanakan pendampingan bagi mitra sasaran yang meliputi pemberian materi mengenai disemianasi teknologi bagi masyarakat, yaitu penerapan teknologi Listrik Hidro Buatan dengan memanfaatkan energi matahari yang diikuti oleh 20 orang peserta. Kegiatan pada tahap II dilaksanakan di Gedung Aula Desa Cimaragas. Setelah pelaksanaan kegiatan pemberian materi dilanjutkan dengan kegiatan demonstrasi perakitan mesin untuk pemanfaatan teknologi Listrik Hidro Buatan dengan memanfaatkan energi matahari.

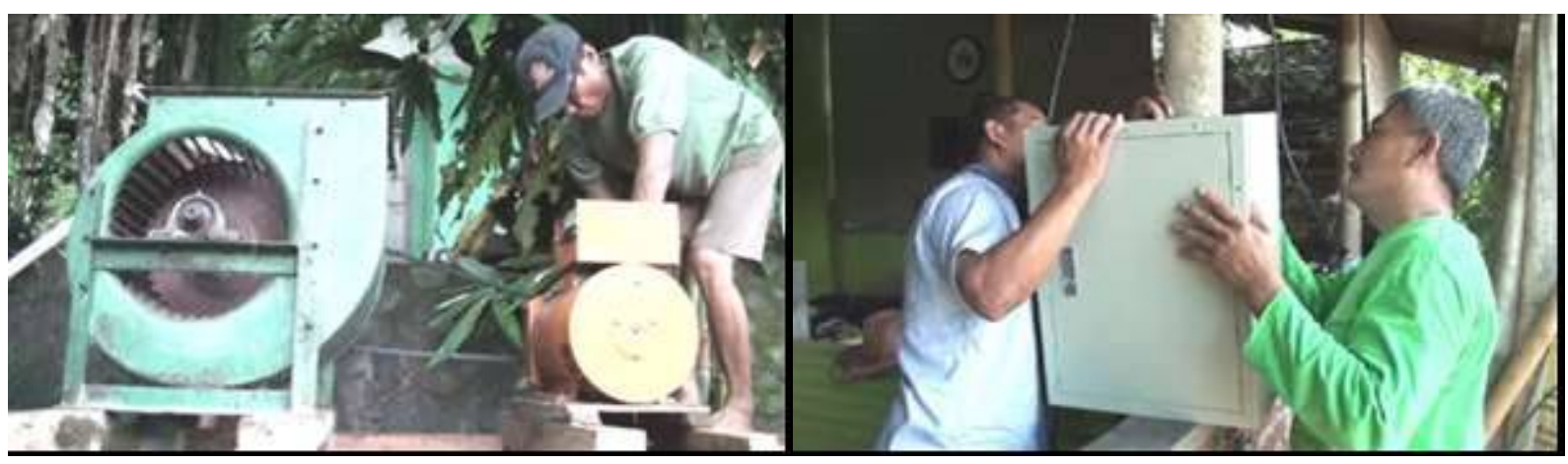

Gambar I. Pelatihan Perakitan Mesin Teknologi Listrik Hidro Buatan dengan memanfaatkan energi matahari

Capaian dari dilaksanakannya kegiatan ini, yaitu terjadi adanya transfer teknologi kepada masyarakat, berupa kemampuan untuk membuat dan merakit teknologi mesin Listrik Hidro Buatan dengan memanfaatkan energi matahari. Hal ini ditunjukan oleh peserta setelah dilakukan pendampingan berupa pemberian materi dan demonstrasi, yaitu mampu merakit dan menyusun struktur bahan untuk penerapan mesin listrik hidro buatan dengan memanfaatkan energi matahari.

Tahap akhir dari pelaksanaan kegiatan PTDM ini adalah diseminasi teknologi untuk IPTEK aplikasi teknologi Listrik Hidro Buatan dengan memanfaatkan energi matahari. Pada kegiatan di tahapan ini, perserta diberikan keleluasaan untuk mempraktekan secara mandiri mekanisme perakitan dan pembuatan mesin teknologi listrik hidro buatan dengan memanfaatkan sumber energi matahari.

Capaian yang ditunjukan pada tahapan ini adalah adanya peningkatan kemampuan masyarakat dalam mengaplikasikan teknologi untuk memanfaatkan sumber energi matahari untuk menggerakkan turbin air sehingga menghasilkan energi listrik hidro buatan yang dapat dimanfaatkan untuk rumah tangga dan industri. Disamping itu, pada kesempatan ini juga dilakukan pengujicobaan energi listrik yang dihasilkan dari teknologi tersebut untuk menggerakan mesin produksi yang diantaranya dipergunakan oleh kelompok usaha di wilayah Desa Cimaragas. 

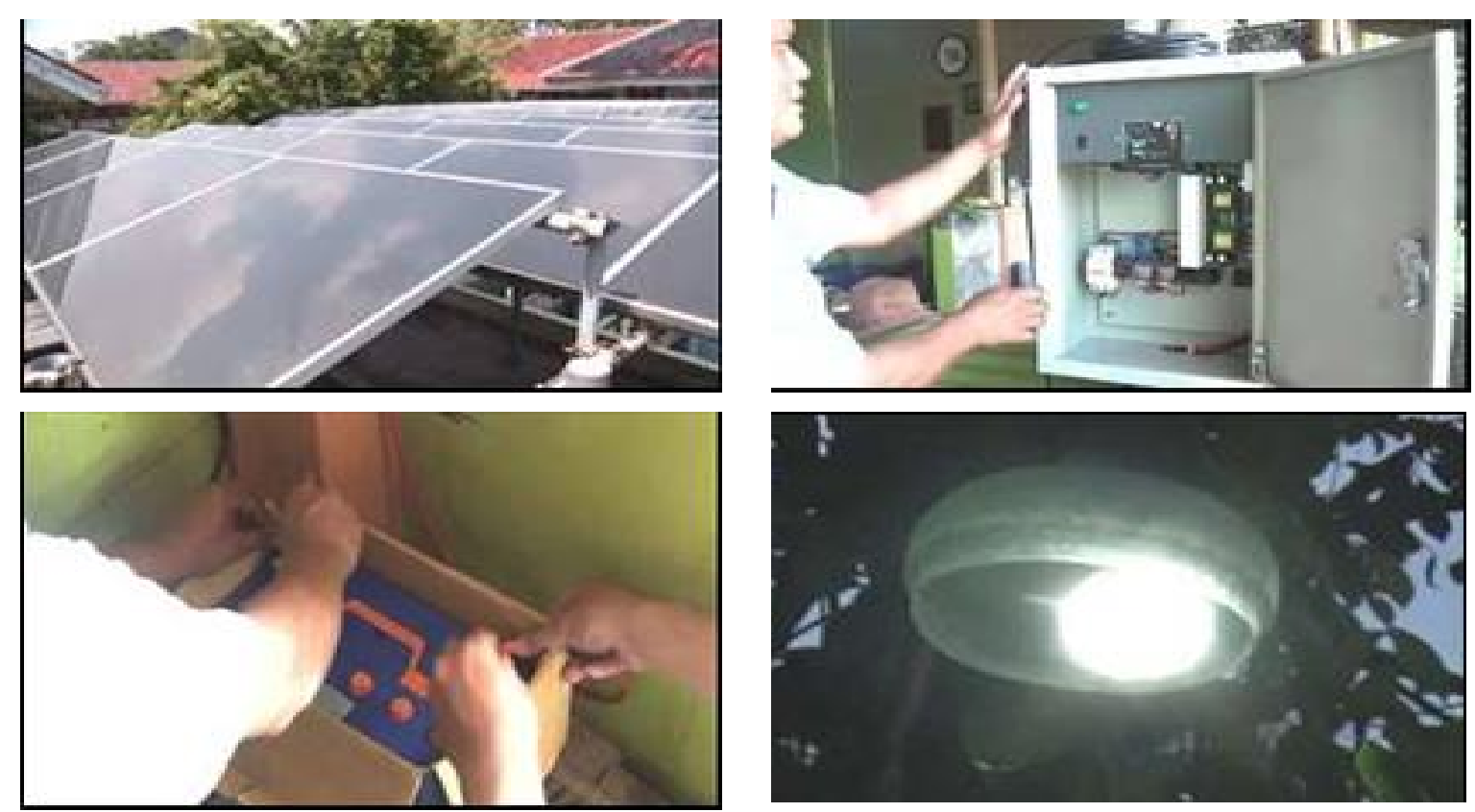

Gambar II. Pelaksanaan Praktek Perakitan dan Pembuatan Mesin Teknologi Listrik Hidro Buatan dengan Memanfaatkan Sumber Energi Matahari

\section{KESIMPULAN DAN SARAN}

Dari hasil tahapan pelaksanaan kegiatan Program Teknologi yang Didiseminasikan kepada masyarakat (PTDM) mengenai Pemanfaatan Tenaga Matahari Sebagai Penggerak Turbin Air Menghasilkan Pembangkit Listrik Hidro Buatan di Desa Cimaragas Kecamatan Cimaragas Kabupaten Ciamis, maka dapat disimpulkan bahwa kondisi mitra saat ini telah mengalami perubahan berupa peningkatkan kapasitas dan kemampuan diri atau life skill khususnya dalam perakitan dan pembuatan teknologi Listrik Hidro Buatan dengan memanfaatkan energi matahari, sekaligus sebagai kesempatan dan peluang untuk mitra dalam mengembangkan hasil teknologi yang lebih memberikan dampak bagi peningkatan kesejahteraan masyarakat dan peningkatan taraf sosial masyarakat.

Disarankan agar kegiatan tersebut memberikan dampak nyata dan luas di masyarakat, diharapkan mitra dapat mendorong mitra untuk menyebarluaskan informasi serupa dan mempraktekan kegiatan yang serupa agar dapat direplikasi di tempat lainnya. Disamping itu, diharapkan penerapan teknologi tersebut sebagai bagian dari hasil inovasi di masyarakat untuk dapat dilombakan pada lomba inovasi daerah.

\section{UCAPAN TERIMAKASIH}

Tim pelaksana kegiatan pengabdian kepada masyarakat dari Universitas Galuh, mengucapkan terima kasih yang sebesar-besarnya kepada DRPM Kemenristek-Brin yang mendukung penuh terselenggaranya Program Teknologi yang Didiseminasikan kepada 
masyarakat (PTDM) sehingga dapat dilaksanakan sesuai dengan harapan. Selanjutnya, ucapan terimkasih disampaikan kepada Universitas Galuh dan Pemerintah Desa Cimaragas Kecamatan Cimargas Kabupaten Ciamis beserta seluruh pihak yang terlibat dalam pelaksanaan kegiatan ini.

\section{DAFTAR PUSTAKA}

Aziz, F. dan Fitri, S.N. 2020. Rancang Bangun Trainer Pembangkit Listrik Mikro Hidro. Journal of Electrical Engginering (Joule), 1(2): 46-49.

Jatmiko, Asy'ari, H. dan Aryo, Hendarto P. 2012. Pemanfaatan Pemandian Umum Untuk Pembangkit Tenaga Listrik Mikrohidro (PLTMh) Menggunakan Kincir Tipe Overshot. Jurnal Emitor, 12(1): 50-58.

Misbachudin, M., Subang, D., Widagdo, T. dan Yunus, M. 2016. Perancangan Pembangkit Listrik Tenaga Mikro Hidro di Desa Kayuni Kabupaten Fakfak Provinsi Papua Barat. Jurnal Austenit, 8(2): 1-12.

Syarif, A., Bow, Y., Ridwan, K.A., Karlini, D. dan Wulandari, S. 2019. Analisis Unjuk Kerja Prototipe Pembangkit Listrik Tenaga Mikrohidro Turbin Pelton Sumber Daya Head Potensial. Jurnal Kinetika, 10( 02): 1- 8

Sunardi, J.P. (2019). Kincir Bertingkat pada Pembangkit Listrik Mikrohidro. AVITEC, 1(1): 71-76. 